\title{
RESISTÊNCIA DE BIÓTIPOS DE EUPHORBIA HETEROPHYLLA L. AOS HERBICIDAS INIBIDORES DA ENZIMA ALS UTILIZADOS NA CULTURA DE SOJA ${ }^{(1)}$
}

\author{
GERSON AUGUSTO GELMINI ${ }^{(2)}$; RICARDO VICTÓRIA FILHO ${ }^{(3)}$; MARIA \\ DO CARMO DE SALVO SOARES NOVO ${ }^{(4)}$; MÁRCIO LUIZ ADORYAN ${ }^{(5)}$

\section{RESUMO}

Os herbicidas constituem-se na principal medida de controle de plantas daninhas na cultura de soja; no entanto, a pressão de seleção causada pelo uso contínuo de produtos com o mesmo mecanismo de ação pode provocar a seleção de biótipos resistentes, como ocorreu com Euphorbia heterophylla L., que se mostrou resistente aos herbicidas inibidores da enzima acetolactato sintase (ALS) em áreas dos Estados do Paraná e Rio Grande do Sul. Para comprovar possíveis novos casos, bem como alternativas para prevenção e manejo, coletaram-se sementes de plantas de E. heterophylla L., na região de Assis (SP), que sobreviveram a tratamentos, em que esses herbicidas foram sistematicamente aplicados nos últimos anos. Desenvolveu-se o experimento em casa de vegetação, comparando-se o biótipo resistente ao suscetível, quando submetido aos diversos herbicidas aplicados em pós-emergência. Aplicaram-se quando as plantas encontravam-se no estádio de duas a quatro folhas verdadeiras, nas doses zero, uma, duas, quatro e oito vezes a recomendada. Aos 20 dias após a aplicação, avaliaram-se os parâmetros relativos ao controle e produção de fitomassa epígea visando ao estabelecimento de curvas de doses-resposta, à obtenção dos fatores de resistência com base nos valores da $\mathrm{DL}_{50}$ e GR50, e à verificação da ocorrência de resistência múltipla. O biótipo resistente apresentou diferentes níveis de resistência aos herbicidas chlorimuron-ethyl e imazethapyr, demonstrando resistência cruzada aos inibidores da ALS dos grupos das sulfoniluréias e imidazolinonas. No entanto, foi eficientemente controlado nos tratamentos com fomesafen $\left(250 \mathrm{~g}^{-h a^{-1}}\right)$, lactofen $\left(120 \mathrm{~g} \cdot \mathrm{ha}^{-1}\right)$, flumiclorac-pentil $\left(40\right.$ g.ha $\left.{ }^{-1}\right)$, glufosinato de amônio $\left(150\right.$ g.ha $\left.{ }^{-1}\right)$ e glyphosate $\left(360\right.$ g.ha $\left.{ }^{-1}\right)$.

Palavras-chave: biótipo resistente, biótipo suscetível, resistência cruzada, imidazolinona, sulfoniluréia, Euphorbiaceae, planta daninha.

\section{ABSTRACT \\ RESISTANCE OF EUPHORBIA HETEROPHYLLA L. BIOTYPES TO ALS ENZYME INHIBITOR HERBICIDES USED IN SOYBEAN CROP}

Herbicides are the main tool for weed control in soybean crop, but the selection pressure attributed to the repeated application of the same herbicides and the same mechanism of action can induce selection of resistant biotypes, such as occurred to Euphorbia heterophylla L. in relation to ALS enzyme inhibitors, in areas of the Paraná and Rio Grande do Sul States, in Brazil. In order to verify possible new cases of resistant populations and to test alternative herbicide treatments to manage this population, seeds of E. heterophylla were collected in the Assis region, State of São Paulo, Brazil, in areas where

${ }^{1}$ ) Recebido para publicação em 22 de janeiro e aceito em 11 de junho de 2001. Parte da tese do primeiro autor apresentada à Escola Superior de Agricultura "Luiz de Queiroz", Universidade de São Paulo (ESALQ/USP), para obtenção do título de Doutor.

$\left({ }^{2}\right)$ Doutorando do Departamento de Produção Vegetal, ESALQ/USP, Caixa Postal 9, 13418-900 Piracicaba (SP).

(3) Departamento de Produção Vegetal, ESALQ/USP.

$\left({ }^{4}\right)$ Centro de Ecofisiologia e Biofísica, Instituto Agronômico (IAC), Caixa Postal 28, 13001-970 Campinas (SP). E-mail: mcdesalvo@hotmail.com

( $\left.{ }^{5}\right)$ Aventis Crop Science do Brasil Ltda., Estação Agrícola Experimental, Caixa Postal 7, 13140-000 Paulínia (SP). 
plants of this species had survived to continuous herbicides application. The trial was carried out in glasshouse conditions where biotypes with a history of suspected resistance were compared with a known susceptible biotype. The study used several post-emergence herbicides sprayed at zero, one, two, four and eight times the recommended field application rates of these products. Twenty days after application, the plants were harvested and the percentage of control and the fresh weight were determined to establish the dose-response curves, to get the resistance factor using data of DL50 and $\mathrm{GR}_{50}$ and to verify if there was a multiple resistance. The resistant biotype showed different resistance levels to chlorimuron-ethyl and imazethapyr, showing cross-resistance to sulfonylurea and imidazolinone groups. Nevertheless, this biotype was efficiently controlled by fomesafen ( 250 g.ha $\left.{ }^{-1}\right)$, lactofen (120 g.ha- $\left.{ }^{-1}\right)$, flumiclorac-pentil $\left(40\right.$ g.ha $\left.{ }^{-1}\right)$, ammonium-gluphosinate (150 g.ha $\left.{ }^{-1}\right)$ and glyphosate (360 g.ha $\left.{ }^{-1}\right)$.

Key words: resistant biotype, susceptible biotype, cross-resistance, imidazolinone, sulfonylurea, Euphorbiaceae, weed.

\section{INTRODUÇÃO}

Entre as técnicas agrícolas adotadas para o desenvolvimento da cultura de soja passíveis de gerenciamento, o manejo das plantas daninhas para minimizar os efeitos da sua indesejável interferência revela-se importante, não só para obtenção de maiores rendimentos por unidade de área (PITELLI, 1985; VelinI, 1997; SPADOtTo e LuChIARI, 1993), como também para a redução dos gastos com insumos e do custo de produção. Embora o manejo dessas plantas possa ser efetuado por diversos métodos, em se tratando de cultura típica de médias e grandes propriedades (Melo FilHo et al., 1996; EmBraPa, 1999), o controle químico vem sendo amplamente adotado, não só devido ao espaçamento de plantio, que dificulta o uso de máquinas, mas, principalmente, em função da grande oferta de herbicidas, da economia de mão-de-obra e da rapidez da operação (BURNSIDE, 1992; EMBRAPA, 1999).

O uso constante de um herbicida ou de herbicidas com o mesmo mecanismo de ação, no entanto, exerce alta pressão de seleção, o que reduz ou elimina indivíduos suscetíveis e, em contrapartida, aumenta o número de indivíduos tolerantes e a manifestação de biótipos resistentes que, provavelmente, já existiam na população, mas em freqüência bastante baixa (Holt e Lebaron, 1990; Christoffoleti et al., 1994; PonChIO, 1997; MAtielo et al., 1999).

No Brasil, constata-se a resistência a herbicidas em algumas plantas daninhas comumente encontradas em soja (EMBrapa, 1999). Em áreas produtoras dos Estados do Paraná e Rio Grande do Sul, verificou-se resistência de Euphorbia heterophylla L., uma das mais importantes espécies daninhas dessa cultura, a herbicidas inibidores de enzima acetolactato sintase ALS (GAZZIERo et al., 1998, VidAl e Merotto Júnior, 1999 e VARGAS et al., 1999a,b). A razão principal para sua manifestação está relacionada com a presença de ALS, insensível à ação desses herbicidas (VIDAL, 1997). Os biótipos mostraram-se, entretanto, suscetíveis a herbicidas com diferentes mecanismos de ação (VIDAL et al., 1997; GazZiero et al., 1998; Vidal e Merotto JúNIOR, 1999; VARGAS et al., 1999a,b).

Considerando o fato de esses biótipos poderem apresentar resistência a outros herbicidas que atuam na mesma enzima, torna-se importante verificar a presença de resistência múltipla a diferentes produtos, cuja atuação se dê em outras enzimas no vegetal, para que a planta daninha possa ser controlada de modo eficaz. Desse modo, este trabalho objetivou: determinar se o biótipo é resistente; estabelecer a magnitude das doses necessárias para provocar $\mathrm{o}$ mesmo efeito em plantas suscetíveis e resistentes; avaliar a presença de resistência múltipla a herbicidas com outros mecanismos de ação, passíveis de serem utilizados em condições de pós-emergência na cultura de soja.

\section{MATERIAL E MÉTODOS}

O experimento foi realizado em casa de vegetação na Estação Experimental da AgrEvo, em Cosmópolis (SP), utilizando-se sementes de Euphorbia heterophylla L. coletadas no final da safra de 1996/97 em aproximadamente 100 plantas que sobreviveram a tratamentos sistemáticos com diversos herbicidas inibidores da ALS, em área produtora de soja na região de Assis (SP). Para efeito de comparação, utilizaram-se sementes de biótipo suscetível coletadas em área próxima àquela com histórico de resistência.

As sementes foram secas ao ar, limpas, acondicionadas em recipientes e armazenadas em câmara refrigerada a $9^{\circ} \mathrm{C}$ e sob controle de umidade a $25 \%$ a fim de possibilitar sua preservação. Para o plantio, realizado em 29/11/98, utilizaram-se vasos plásticos perfurados, com capacidade para $1,3 \mathrm{~L}-14,8 \mathrm{~cm}$ no diâmetro maior, $9,8 \mathrm{~cm}$ no menor e $12,2 \mathrm{~cm}$ de altura - que receberam substrato composto por três partes de terra para uma de húmus, previamente tratado com brometo de metila para eliminar possíveis contaminantes. Os resultados das análises química e física 
do substrato foram os seguintes: P: $185 \mathrm{mg} \cdot \mathrm{dm}^{-3}$; matéria orgânica: $18,8 \mathrm{~g} . \mathrm{dm}^{-3}$; CTC: $128 \mathrm{mmol}_{\mathrm{c}} \cdot \mathrm{dm}^{-3}$; V: $79,8 \%$; areia: $11,8 \%$ e argila, $10,2 \%$.

Foram semeadas dez sementes por recipiente e, após a germinação, efetuou-se o desbaste, deixandose quatro plântulas e, sempre que necessário, utilizouse de irrigação para manter o substrato com boas condições de umidade.

O experimento foi disposto em blocos ao acaso com quatro repetições, comparando-se o biótipo resistente e o suscetível, quando tratados ou não com herbicidas recomendados para a cultura de soja, aplicados em pós-emergência, ou seja: chlorimuron-ethyl a $0,15,30,60$ e 120 g.ha $^{-1}$; imazethapyr a 0, 100, 200, 400 e 800 g.ha ${ }^{-1}$; fomesafen a 0, 250, 500, 1.000 e 2.000 g.ha ${ }^{-1}$; lactofen a $0,120,240,480$ e 960 g.ha $^{-1}$; flumiclorac-pentil a $0,40,80,160$ e 320 g.ha ${ }^{-1}$; glufosinato de amônio a 0, 150, 300, 600 e 1.200 g.ha $^{-1}$ e glyphosate a 0, 180, 360, 720 e 1.440 g.ha ${ }^{-1}$. Adicionaram-se às caldas de pulverização de chlorimuronethyl, flumiclorac-pentil, fomesafen e glufosinato de amônio, respectivamente, óleo mineral emulsionável a 0,05 e $0,2 \%(\mathrm{v} / \mathrm{v})$, adjuvante à base de nonil fenol oxietilado a $0,2 \%(\mathrm{v} / \mathrm{v})$ e álcool isopropílico a $0,2 \%$ (v/v).

Os herbicidas foram aplicados em 12/12/98, quando as plântulas apresentaram duas a quatro folhas verdadeiras, empregando-se pulverizador de precisão, pressurizado, tendo como gás propelente ar comprimido, equipado com barra de seis bicos de jato plano, tipo leque (XR 110.015), espaçados em 0,40 m e mantidos a $0,50 \mathrm{~m}$ de superfície do solo. A pressão de trabalho de 2,5 bar possibilitou consumo correspondente a 200 L.ha $^{-1}$ de calda.

Realizou-se a avaliação 20 dias após a aplicação, empregando-se escala de notas, em porcentagem, em que a ausência de injúria correspondeu ao valor zero e a morte da planta, ao valor 100 . Nessa mesma época, as plantas de todos os tratamentos foram cortadas rente ao solo e pesadas, a fim de obter a fitomassa epígea. Por ocasião da análise estatística, fez-se um estudo para verificação da homocedasticidade dos dados. Para isso, empregou-se o teste de Hartley $\left(F_{\text {máx }}\right)$. Como foi verificado que havia heterocedasticidade regular para os dados de porcentagem, estes foram transformados em arco seno $(x / 100)^{1 / 2}$. Os dados foram submetidos à análise da variância, empregando-se o teste $\mathrm{F}$.

As médias dos tratamentos com herbicidas e a comparação entre os dois biótipos, quando significativas, foram comparadas pelo teste de Tukey ao nível de $5 \%$. Efetuou-se a análise do efeito de doses de herbicidas para cada biótipo, empregando-se o programa Curve Expert 1.3. Cada conjunto foi caracteri- zado pela equação de ajuste que melhor representou o comportamento da variável dentro de cada biótipo em relação ao efeito dos tratamentos com os herbicidas e suas doses, sendo consideradas as equações em que os coeficientes de determinação $\left(R^{2}\right)$ foram iguais ou superiores a 0,96 e tinham significado biológico, sendo discutidos apenas os desdobramentos da análise em que o teste $\mathrm{F}$ foi significativo.

Para comparação das respostas, calculou-se, com base em equações de ajuste, a dose que provocou $50 \%$ de controle ( $\left.\mathrm{DL}_{50}\right)$ ou a porcentagem de redução na produção de fitomassa epígea em relação à testemunha $\left(\mathrm{GR}_{50}\right)$. Considerando-se esses valores, determinou-se o fator de resistência (FR), que representa o número de vezes em que a dose necessária para proporcionar $50 \%$ de controle ou de redução na produção de fitomassa epígea do biótipo suscetível deve ser aumentada, para que possa ocorrer o mesmo efeito sobre o resistente, segundo método descrito por GAZZIERO et al. (1998).

\section{RESULTADOS E DISCUSSÃO}

Os resultados mostraram que apenas chlorimuron-ethyl e imazethapyr não controlaram o biótipo com histórico de resistência, uma vez que os índices encontrados situaram-se muito abaixo do mínimo aceitável e dos valores obtidos com o material suscetível (Quadro 1).

$\mathrm{O}$ índice de controle para o biótipo resistente (BR) variou de $4 \%$ a $6 \%$ para chlorimuron-ethyl e de $5 \%$ a $12 \%$ para imazethapyr; no biótipo suscetível (BS), entre $79 \%$ e $94 \%$ para chlorimuron-ethyl e $85 \%$ e $95 \%$ para imazethapyr. No que se refere à fitomassa epígea, observou-se que, para ambos os herbicidas, a porcentagem de produção em relação à testemunha no BR foi igual à da testemunha, ao passo que no BS variou de $5 \%$ a $13 \%$ e de $3 \%$ a $11 \%$ respectivamente.

As curvas de dose-resposta para os dois biótipos, relativas ao chlorimuron-ethyl e imazethapyr, são apresentadas na figura 1. Quanto à porcentagem de controle do BR, as equações de ajuste, tanto de chlorimuron-ethyl, como de imazethapyr, seguiram o modelo de Harris; para o suscetível, a associação exponencial mostrou-se mais adequada. Os dados de produção de fitomassa epígea em relação à testemunha, do biótipo resistente, para chlorimuron-ethyl, seguiram ajuste exponencial, e para o suscetível, não. Já para imazethapyr, tanto o suscetível como o resistente foram mais bem ajustados por equação exponencial (Quadro 2). 
G.A. GELMINI et al.

Quadro 1. Porcentagem de controle e produção de fitomassa epígea dos biótipos resistentes (BR) e suscetível (BS) de Euphorbia heterophylla L., 20 dias após a aplicação dos herbicidas de pós-emergência. Cosmópolis (SP), 1998

\begin{tabular}{|c|c|c|c|c|c|}
\hline \multirow{2}{*}{ Tratamentos } & \multirow{2}{*}{ Dose } & \multicolumn{2}{|c|}{ Controle $\left({ }^{1}\right)$} & \multicolumn{2}{|c|}{ Fitomassa epígea $\left(^{2}\right)$} \\
\hline & & $\mathrm{BR}$ & BS & $\mathrm{BR}$ & BS \\
\hline & g.ha ${ }^{-1}$ & \multicolumn{2}{|c|}{$\%$} & \multicolumn{2}{|c|}{$\%$} \\
\hline & 0 & $0 \mathrm{a}$ & $0 \mathrm{a}$ & $100,0 \mathrm{a}$ & $100,0 \mathrm{a}$ \\
\hline & 15 & $4,0 \mathrm{~b}$ & $79,5 \mathrm{a}$ & 99,6 a & $12,3 \mathrm{~b}$ \\
\hline \multirow[t]{5}{*}{ Chlorimuron-ethyl } & 30 & $5,0 \mathrm{~b}$ & $83,7 \mathrm{a}$ & 99,3 a & $8,5 \mathrm{~b}$ \\
\hline & 60 & $5,0 \mathrm{~b}$ & $92,5 \mathrm{a}$ & $99,3 \mathrm{a}$ & $5,1 \mathrm{~b}$ \\
\hline & 120 & $5,7 \mathrm{~b}$ & 93,7 a & 98,5 a & $5,1 \mathrm{~b}$ \\
\hline & 0 & $0,0 \mathrm{a}$ & $0,0 \mathrm{a}$ & $100,0 \mathrm{a}$ & $100,0 \mathrm{a}$ \\
\hline & 100 & $5,0 \mathrm{~b}$ & $85,0 \mathrm{a}$ & 99,2 a & $10,8 \mathrm{~b}$ \\
\hline \multirow[t]{5}{*}{ Imazethapyr } & 200 & $5,7 \mathrm{~b}$ & 87,5 a & 99,9 a & $10,4 \mathrm{~b}$ \\
\hline & 400 & $7,5 \mathrm{~b}$ & $90,0 \mathrm{a}$ & $99,1 \mathrm{a}$ & $6,8 \mathrm{~b}$ \\
\hline & 800 & $11,2 \mathrm{~b}$ & $94,5 \mathrm{a}$ & $99,2 \mathrm{a}$ & $3,5 \mathrm{~b}$ \\
\hline & 0 & 0 & 0 & 100,0 & 100,0 \\
\hline & 250 & 83,7 & 83,7 & 13,3 & 10,9 \\
\hline \multirow[t]{5}{*}{ Fomesafen } & 500 & 88,7 & 91,2 & 10,2 & 8,7 \\
\hline & 1.000 & 93,7 & 95,0 & 9,3 & 5,7 \\
\hline & 2.000 & 97,7 & 97,5 & 6,8 & 3,1 \\
\hline & 0 & 0 & 0 & 100,0 & 100,0 \\
\hline & 120 & 88,2 & 82,5 & 10,0 & 11,1 \\
\hline \multirow[t]{5}{*}{ Lactofen } & 240 & 94,5 & 90,0 & 7,4 & 8,0 \\
\hline & 480 & 97,5 & 96,2 & 4,2 & 5,1 \\
\hline & 960 & 99,5 & 100,0 & 1,9 & 2,8 \\
\hline & 0 & 0 & 0 & 100,0 & 100,0 \\
\hline & 720 & 88,7 & 87,7 & 7,9 & 11,9 \\
\hline \multirow[t]{5}{*}{ Flumiclorac-pentil } & 1.440 & 93,7 & 93,7 & 7,4 & 8,4 \\
\hline & 2.880 & 94,5 & 95,0 & 7,5 & 7,3 \\
\hline & 5.760 & 95,5 & 95,7 & 6,7 & 3,4 \\
\hline & 0 & 0 & 0 & 100,0 & 100,0 \\
\hline & 150 & 81,2 & 82,5 & 9,8 & 11,6 \\
\hline \multirow[t]{5}{*}{ Glufosinato de amônio } & 300 & 91,2 & 91,2 & 10,7 & 8,8 \\
\hline & 600 & 97,5 & 97,2 & 7,1 & 5,3 \\
\hline & 1.200 & 98,7 & 97,7 & 6,2 & 3,5 \\
\hline & 0 & 0 & 0 & 100,0 & 100,0 \\
\hline & 180 & 56,2 & 56,2 & 21,2 & 20,3 \\
\hline \multirow[t]{3}{*}{ Glyphosate } & 360 & 86,2 & 87,5 & 14,3 & 17,9 \\
\hline & 720 & 99,0 & 99,0 & 4,2 & 4,5 \\
\hline & 1.440 & 100,0 & 99,5 & 3,7 & 3,4 \\
\hline DMS 5\% & & \multicolumn{2}{|c|}{2,79} & \multicolumn{2}{|c|}{2,95} \\
\hline CV\% & & \multicolumn{2}{|c|}{3,20} & \multicolumn{2}{|c|}{5,72} \\
\hline
\end{tabular}

$\left(^{1}\right)$ Dados transformados em arco seno $(x / 100)^{1 / 2} \cdot\left({ }^{2}\right)$ Produção de fitomassa epígea, em porcentagem, em relação à testemunha. Dados transformados em arco seno $(\mathrm{x} / 100)^{1 / 2}$. Médias seguidas da mesma letra não diferem entre si pelo teste de Tukey a $5 \%$ de probabilidade. 

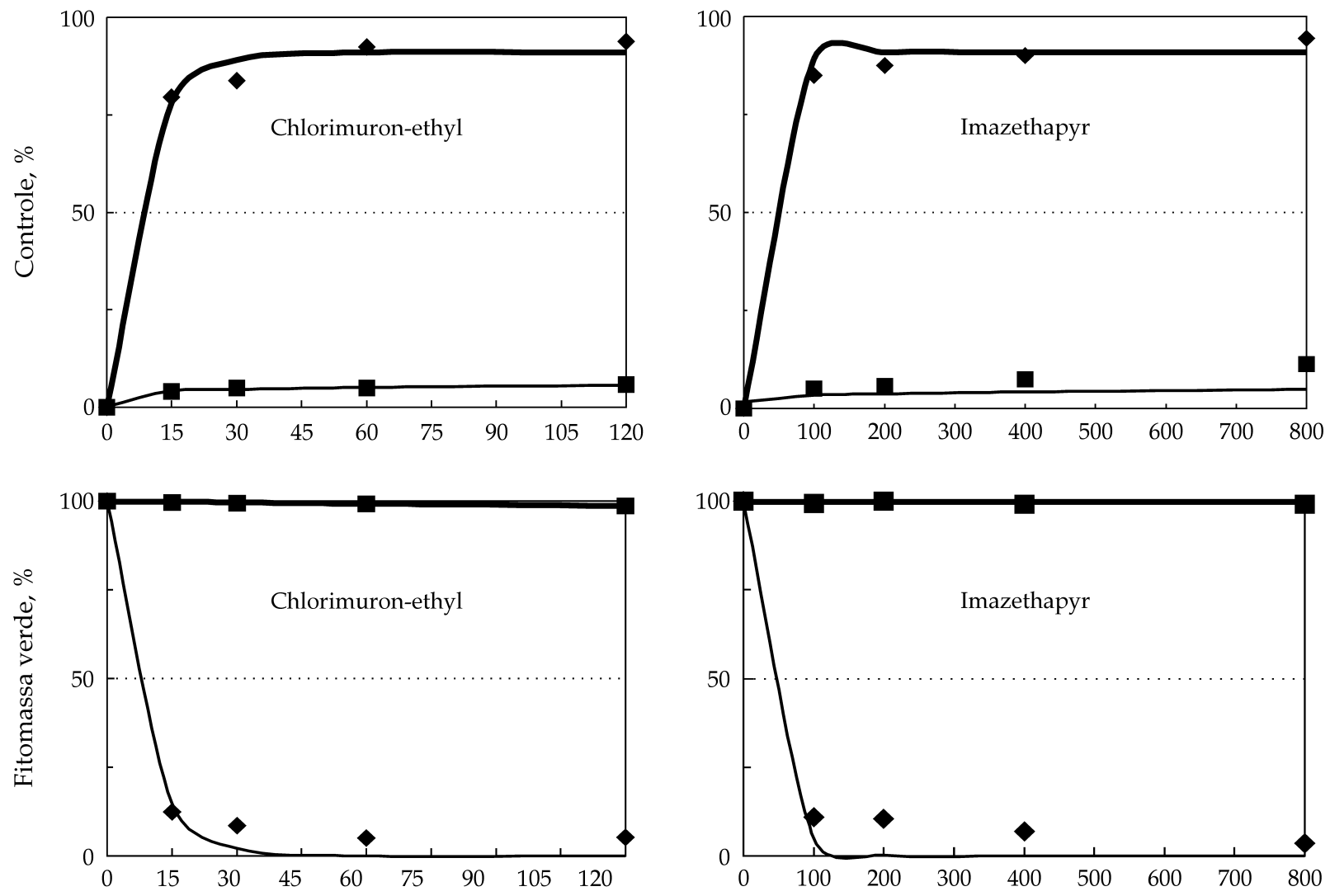

Dose, g.ha-1

\begin{tabular}{|cc|}
\hline biótipo resistente ajustado & biótipo resistente observado \\
biótipo suscetível ajustado & $\bullet$ biótipo suscetível observado \\
\hline
\end{tabular}

Figura 1. Curvas de doses-resposta dos herbicidas clorimuron-ethyl e imazethapyr para os biótipos resistente e suscetível de Euphorbia heterophylla L. Cosmópolis (SP), 1998.

Os valores de $\mathrm{DL}_{50}$ e $\mathrm{GR}_{50}$, calculados a partir das equações, mostraram que mesmo quando se aplicou dose oito vezes maior do que a recomendada de chlorimuron-ethyl e de imazethapyr, o biótipo resistente não foi controlado nem houve redução na produção de fitomassa epígea. Para o biótipo suscetível, a dose recomendada foi eficaz (Quadro 3).

$\mathrm{O}$ fator de resistência para chlorimuron-ethyl foi superior a $19 \%$ para a porcentagem de controle e a $22 \%$ para a produção de fitomassa epígea; para imazethapyr, o fator de resistência foi superior a $26 \%$ e $23 \%$, respectivamente, para porcentagem de controle e produção de fitomassa epígea (Quadro 3). O fato evidencia a manifestação de resistência cruzada aos inibidores de ALS representados por esses herbicidas dos grupos das sulfoniluréias e imidazolinonas, conforme preconizado por Powles e Howat (1990), CHRISTOFFoleti e CORTEZ (1999) e VARGAS et al. (1999a,b) e em consonância com os anteriormente obtidos por
GAZZIERO et al. (1998); VArGAS et al. (1999b) e VidAL e MEROtTO JúNIOR (1999). Uma vez que a resistência foi manifestada em doses acima das recomendadas, os resultados estão de acordo com os de GRESSEL e SEGEL (1978), Holt e LEBARON (1990) e WARWICK (1991), admitindo-se a hipótese de ter sido induzida pelo uso contínuo e prolongado de herbicidas com o mesmo mecanismo de ação, conforme afirma BETTS et al. (1992). Sua manifestação pode estar relacionada com a presença de genótipos que sobreviviam na comunidade original em níveis bastante baixos, como considerado por Guttieri et al. (1992) e Mattielo et al. (1999).

Por outro lado, verificou-se que os herbicidas de aplicação em pós-emergência total, tradicionalmente utilizados na cultura da soja, como fomesafen $\left(250\right.$ g.ha $\left.^{-1}\right)$, lactofen $\left(120\right.$ g.ha $\left.^{-1}\right)$ e flumiclorac-pentil $\left(40\right.$ g.ha $\left.{ }^{-1}\right)$, além do glufosinato de amônio $\left(150 \mathrm{~g} \cdot \mathrm{ha}^{-1}\right)$ e glyphosate (360 g.ha ${ }^{-1}$ ) com seus respectivos adju- 
Quadro 2. Equações de ajuste das porcentagens de controle e de produção de fitomassa epígea para chlorimuron-ethyl e imazethapyr, referentes aos biótipos resistente (BR) e suscetível (BS) de Euphorbia heterophylla L. Cosmópolis (SP), 1998

\begin{tabular}{lll}
\hline Biótipo & \multicolumn{1}{c}{ Controle } & Fitomassa epígea \\
\cline { 2 - 3 } Chlorimuron-ethyl & & \\
\multicolumn{1}{l}{ BR } & $\mathrm{y}=\left(9,04-8,719 \mathrm{x}^{0,0034}\right)^{-1}$ & $\mathrm{y}=99,90\left(\mathrm{e}^{-0,00011 \mathrm{x}}\right)$ \\
BS & $\mathrm{y}=91,02\left(1-\mathrm{e}^{0,129 \mathrm{x}}\right)$ & $\mathrm{y}=99,86\left(0,88^{\mathrm{x}}\right)$ \\
Imazethapyr & & $\mathrm{y}=99,78\left(\mathrm{e}^{-0,0000083 \mathrm{x}}\right)$ \\
BR & $\mathrm{y}=\left(0,576-0,186 \mathrm{x}^{0,144}\right)^{-1}$ & $\mathrm{y}=99,84\left(\mathrm{e}^{-0,202 \mathrm{x}}\right)$ \\
\hline
\end{tabular}

Quadro 3. Valores de DL50, GR50 e FR dos herbicidas chlorimuron-ethyl e imazethapyr referentes ao controle e produção de fitomassa epígea nos biótipos resistente (BR) e suscetível (BS) de Euphorbia heterophylla L. Cosmópolis (SP), 1998

\begin{tabular}{|c|c|c|c|c|c|}
\hline \multirow{2}{*}{ Biótipo } & \multicolumn{2}{|c|}{ Controle } & \multirow{2}{*}{ Biótipo } & \multicolumn{2}{|c|}{ Fitomassa epígea } \\
\hline & LD50 & FR & & $\mathrm{GR}_{50}$ & FR \\
\hline & 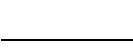 & _ & & 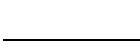 & 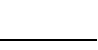 \\
\hline \multicolumn{6}{|c|}{ Chlorimuron-ethyl } \\
\hline BR & $>120$ & - & ER & $>120$ & - \\
\hline BS & 6,19 & $>19,39$ & ES & 5,33 & $>22,51$ \\
\hline \multicolumn{6}{|c|}{ Imazethapyr } \\
\hline BR & $>800$ & - & ER & $>800$ & - \\
\hline BS & 30,00 & $>26,67$ & ES & 34,24 & $>23,36$ \\
\hline
\end{tabular}

vantes adicionados à calda de pulverização, exerceram controle eficaz (Quadro 2), tornando-se importantes opções, não só para minimizar os efeitos da seleção indesejável, mas também para o manejo dessa população resistente. Em biótipos com resistência aos inibidores da ALS, VIDAL (1997) verificaram o eficiente controle proporcionado por fomesafen, lactofen e glyphosate; GAZZIERO et al. (1998) identificaram lactofen e sulfentrazone como alternativas viáveis; VARGAS et al. (1999a,b) observaram o eficiente controle do biótipo resistente quando submetido a tratamentos com fomesafen, lactofen, glyphosate e glufosinato de amônio aplicados nas doses recomendadas, enquanto Buzatti (1999) e SiLva (1999) indicaram, nessa situação, o uso de alternativas como fomesafen e lactofen.

\section{CONCLUSÕES}

1. O biótipo resistente apresentou diferentes níveis de resistência aos herbicidas chlorimuron-ethyl e imazethapyr, demonstrando ser portador de resistên- cia cruzada aos inibidores da ALS dos grupos da sulfoniluréia e imidazolinona.

2. O biótipo resistente foi eficientemente controlado pelos herbicidas fomesafen $\left(250 \mathrm{~g}^{-1} \mathrm{a}^{-1}\right)$, lactofen $\left(120\right.$ g.ha $\left.^{-1}\right)$, flumiclorac-pentil $\left(40\right.$ g.ha $\left.{ }^{-1}\right)$, glufosinato de amônio (150 g.ha' $\left.{ }^{-1}\right)$ e glyphosate $\left(180\right.$ g.ha $\left.^{-1}\right)$, demonstrando não apresentar resistência múltipla aos inibidores de Protox, GS e EPSEs, que podem ser utilizados para minimizar os efeitos de seleção e efetuar o manejo da população resistente.

\section{REFERÊNCIAS BIBLIOGRÁFICAS}

BETTS, K.J.; EHLKE, N.J.; WYSE, D.L.; GRONWALD, J.W.; SOMERS, D.A. Mechanism of inheritance of diclofop resistance in Italian ryegrass (Lolium multiflorum). Weed Science, Champaign, v.40, n.2, p.184-189, 1992.

BURNSIDE, O.C. Rationale for developing herbicide-resistant crops. Weed Technology, Champaign, v.6, n.3, p.621-625, 1992.

BUZATTI, W.J.S. Casos de resistência de plantas daninhas de leiteiro (Euphorbia heterophylla) e papuã (Brachiaria plantaginea) na região dos Campos Gerais do Paraná. 
In: CURSO DE MANEJO DA RESISTÊNCIA DE PLANTAS DANINHAS AOS HERBICIDAS, 2., 1999. Anais... Ponta Grossa: AECG, 1999, p.132-140.

CHRISTOFFOLETI, P.J.; CORTEZ, M.G. Resistência de plantas daninhas aos herbicidas. In: CURSO DE MANEJO DA RESISTÊNCIA DE PLANTAS DANINHAS AOS HERBICIDAS, 2., 1999, Ponta Grossa. Anais... Ponta Grossa: AECG, 1999. p.74-100.

CHRISTOFFOLETI, P.J.; VICTORIA FILHO, R.; SILVA, C.B. Resistência de plantas daninhas aos herbicidas. Planta Daninha, Brasília, v.12, n.1, p.13-20, 1994.

EMBRAPA. Recomendações técnicas para a cultura da soja na região central do Brasil 1999/2000. Londrina: CNPSo, 1999. 226p. (Embrapa Soja. Documentos, 132; Embrapa Agropecuária Oeste, 5)

GAZZIERO, D.L.P.; BRIGHENTI, A.M., MACIEL, C.D.G.; CHRISTOFFOLETI, P.J.; ADEGAS, F.S.; VOLL, E. Resistência de amendoim-bravo aos herbicidas inibidores da enzima ALS. Planta Daninha, Londrina: v.16, n.2, p.117-125, 1998.

GRESSEL, J.; SEGEL, L.A. The pancity of genetic adaptative resistance of plants to herbicides: possible biological reasons and implications. Journal of Theorical Biology, Washington, v.75, n.3, p.349-371, 1978.

GUTIERRI, M.J.; EBERLEIN, C.V.; MALLORY-SMITH, C.A.; THILL, D.C.; HOFFMAN, D.L. DNA sequence variation in domain $\mathrm{A}$ of the acetolactate synthase genes of herbicide-resistant and susceptible weed biotypes. Weed Science, Champaign, v.40, p.670-676, 1992.

HOLT, J.S.; LEBARON, H.M. Significance and distribution of herbicide resistance. Weed Technology, Champaign, v.4, n.1, p.141-149, 1990.

MATTIELO, R.R.; RONZELI JÚNIOR, P.; PURÍSSIMO, C. Mecanismos de resistência: fatores biológicos, agronômicos e genéticos. In: CURSO DE MANEJO DA RESISTÊNCIA DE PLANTAS DANINHAS AOS HERBICIDAS, 2., 1999, Ponta Grossa. Anais... Ponta Grossa: AECG, 1999. p.27-40.

MELO FILHO, G.A.; RICHETTI, A.; PARIZOTO, A.M. Aspectos socioeconômicos da cultura da soja. In: Recomendações técnicas para Mato Grosso do Sul e Mato Grosso. Dourados: CPAO, 1996. p.29-33. (EMBRAPA/ CNPAO - Circular Técnica, 3)

PITELLI, R.A. Interferência de plantas daninhas em culturas agrícolas. Informe Agropecuário, Belo Horizonte, v.11, n.129, p.16-27, 1985.
PONCHIO, J.A.R. Resistência de Bidens pilosa L. aos herbicidas inibidores da enzima acetolactato sintase. Piracicaba, 1997. 138p. Tese (Doutorado) - Escola Superior de Agricultura "Luiz de Queiroz", Universidade de São Paulo.

POWLES, S.B.; HOWAT, P.D. Herbicide-resistant weeds in Australia. Weed Technology, Champaign, v.4, n.1, p.178-185, 1990.

SILVA, U.G. Estratégias de manejo de populações resistentes: manejo da planta daninha amendoim-bravo (Euphorbia heterophylla - REPHHL-R) resistente aos herbicidas inibidores da enzima ALS. In: CURSO DE MANEJO DE RESISTENNCIA DE PLANTAS DANINHAS AOS HERBICIDAS, 2., 1999, Ponta Grossa. Anais... Ponta Grossa: AECG, 1999. p.141-148.

SPADOTTO, C.A.; LUCHIARI, F. Índice de competitividade de espécies de plantas daninhas com a soja. In: CONGRESSO BRASILEIRO DE HERBICIDAS E PLANTAS DANINHAS, 19., 1993, Londrina. Resumos... Londrina: SBHPD, 1993. p.66.

VARGAS, L.; SILVA, A.A. da; BORÉM, A.; OLIVEIRA, S.P de. Identificação e manejo de plantas daninhas resistentes a herbicidas. Viçosa: Jard, 1999a. 39p.

VARGAS, L.; SILVA, A.A. da; BORÉM, A.; REZENDE, S.T.; FERREIRA, F.A; SEDIYAMA, T. Resistência de plantas daninhas a herbicidas. Viçosa: Jard, 1999b. 131p.

VELINI, E.D. Interferências entre plantas daninhas e cultivadas. In: SIMPÓSIO SOBRE HERBICIDAS E PLANTAS DANINHAS, 1., 1997, Dourados. Resumos... Dourados: EMBRAPA-CPAO, 1997. p.29-49.

VIDAL, R.A. Herbicidas: mecanismos de ação e resistência de plantas. Porto Alegre: R.A. Vidal, 1997. 165p.

VIDAL, R.A.; FLECK, N.G.; THEISEN, G.; NEVES, R.; PETRY, L.A. Picão-preto e leiteira resistentes aos inibidores de ALS apresentam resistência aos herbicidas com diferentes mecanismos de ação. In: CONGRESSO BRASILEIRO DA CIÊNCIA DAS PLANTAS DANINHAS, 21., 1997, Caxambu. Resumos... Viçosa: SBCPD, 1997. p.465.

VIDAL, R.A.; MEROTTO JÚNIOR, A. Resistência de amendoim-bravo aos herbicidas inibidores da enzima acetolactato sintase. Planta Daninha, Londrina, v.17, n.3, p.367-373, 1999.

WARWICK, S.I. Herbicide resistance in weedy plants: physiology and population biology. Annual Review of Ecology and Systematic, Palo Alto, v.22, p.95-144, 1991. 